\title{
Effect of nanoparticles on heat transfer in mini double-pipe heat exchangers in turbulent flow
}

\author{
Reza Aghayari · Heydar Maddah · Fatemeh Ashori • \\ Afshin Hakiminejad $\cdot$ Mehdi Aghili
}

Received: 31 October 2013/ Accepted: 3 July 2014/Published online: 25 July 2014

(C) Springer-Verlag Berlin Heidelberg 2014

\begin{abstract}
In this work, heat transfer of a fluid containing nanoparticles of aluminum oxide with the water volume fraction $(0.1-0.3)$ percent has been reported. Heat transfer of the fluid containing nano water aluminum oxide with a diameter of about $20 \mathrm{~nm}$ in a horizontal double pipe counter flow heat exchanger under turbulent flow conditions was studied. The results showed that the heat transfer of nanofluid in comparison with the heat transfer of fluid is slightly higher than 12 percent.
\end{abstract}

\section{Introduction}

The various types of heat exchangers such as double pipe and plate heat exchangers (PHE) are widely used in food and chemical processing industries. The plate or corrugated plate heat exchangers are replacing conventional concentric or double pipe heat exchangers. A plate heat exchanger is a type of heat exchanger that uses metal plates to transfer

R. Aghayari $(\bowtie) \cdot$ F. Ashori $\cdot$ M. Aghili

Shahrood Branch, Islamic Azad University, Shahrood, Iran

e-mail: Reza.aghayari63@yahoo.com

F. Ashori

e-mail: Fa_ashori@yahoo.com

M. Aghili

e-mail: Mehdiaghili563@gmail.com

H. Maddah

Department of Chemistry, Faculty of Sciences,

University of Arak, Arāk, Iran

e-mail: madah.2007@gmail.com

A. Hakiminejad

Alborz Institution of Higher Education, Qazvin, Iran

e-mail: hakimi.afshin@yahoo.com heat between two fluids. This has a major advantage over a conventional heat exchanger in that the fluids are exposed to a much larger surface area because the fluids spread out over the plates $[1,2]$. A plate heat exchanger consists of a series of thin and corrugated plates. These plates are gasketed, welded or brazed together depending on the application of the heat exchanger. The plates are compressed together in a rigid frame to form an arrangement of parallel flow channels with alternating hot and cold fluids. To enhance the thermal efficiency of the heat exchangers, the thermal capability of the working fluid must increase [3, 4]. Addition of small amount of high thermal conductivity solid nanoparticles in base fluid increases the thermal conductivity, thus increasing the heat transfer rate in the heat exchangers [5-8]. Nanofluid is the name conceived by Argonne National Laboratory (ANL), USA, to describe a fluid in which nanometer-sized particles are suspended. Nanofluids are a class of heat transfer fluids created by dispersing solid nanoparticles in traditional heat transfer fluids. Research results showed that nanofluids have thermal properties that are very different from those of conventional heat transfer fluids such as water or ethylene glycol. The ANL performed nanofluid experiment, where it was found a $20 \%$ increase in the thermal conductivity. Theoretically the thermal conductivity increases are based on the volume fraction and shape of the particles. The increase of the thermal conductivity leads to an increase in heat transfer performance. In fact the reduction of the thermal boundary layer thickness due to the presence of the nanoparticles and the random motion within the base fluid may have important contributions to such heat transfer improvement as well [9-11]. Nanofluids were first used by Choi [12]. He showed that addition of small amount of nanoparticles to the base fluids increased the thermal conductivity of the fluids up to approximately two times. 
Many experimental works have been attempted in the nanofluids area. Some of these works are focused on use of nanofluids in the circular pipes or in the heat exchangers. Yang et al. [13] reported experimental results which illustrated the convective heat transfer coefficient of graphite nanoparticles dispersed in liquid for laminar flow in a horizontal tube heat exchanger. Effects of the Reynolds number, volume fraction, temperature, nanoparticle source, and type of base fluid on the convective heat transfer coefficient have been investigated. The experimental results showed that the heat transfer coefficient increased with the Reynolds number and the particle concentration. For example at $2.5 \mathrm{wt} \%$ the heat transfer coefficient of the nanofluids were $22 \%$ higher than the base fluid at $50{ }^{\circ} \mathrm{C}$ fluid temperature and $15 \%$ higher at $70{ }^{\circ} \mathrm{C}$. Wen et al. [14] presented an experimental study which evaluated the convective heat transfer coefficient of $\mathrm{Al}_{2} \mathrm{O}_{3}$ nanoparticles suspended in deionized water for laminar flow in a copper tube, focusing in particular on the entrance region. The various concentrations of nanoparticles $(0.6,1.0$, and $1.6 \%)$ were tested under a constant wall heat flux. The results showed that the use of nanofluids affected a pronounced increase in the heat transfer coefficient causing a decrease in the thermal boundary layer thickness and a decrease along the tube length. High accumulation of nanoparticles in the thermal boundary layer near the wall resulting from particles migration phenomenon may be one of the reasons of the increase of heat transfer in nanofluids. Assuming the small size and low friction for particles, nanofluid is homogenious. Under these conditions, general and principal relations of heat transfer for nanofluids are applicable. If it is assumed that nanoparticles have been dispersed in the fluid, dispersion of the particles in the pipe would be homogenious. Although this consumption is not true in real systems due to the particles migration phenomenon, it is a useful way for estimating the nanofluid physical features. The aim of this study is to investigate the effect of alumina nanoparticles in the fluid on the heat transfer in double pipe heat exchangers to identify the role of nanofluids in the increase of heat performance of heat exchangers and to use these nanofluids in the industrial applications.

\section{Experimental}

\subsection{Experimental setup}

A schematic of the experimental setup used to investigate heat transfer characteristics of nanofluid in a mini heat exchanger is shown in Figs. 1 and 2. It consists of two flow loops, a heating unit to heat the nanofluid, and temperature measurement system. The two flow loops carried heated nanofluid and the other cooling water. Each flow loop included a pump with a flow meter, a reservoir and a bypass valve. Four J-type thermocouples (accuracy at $0.1 \%$, uncertainty at $\pm 0.1{ }^{\circ} \mathrm{C}$ ) were inserted on the heat exchanger to measure the temperatures of inlet and exit fluid streams. All temperatures were recorded using a thermocouple scanner. The pumps used were magnetic drive centrifugal type with a maximum delivery rate of $90 \mathrm{~g} / \mathrm{s}$. Other specs included: the length of test section was $120 \mathrm{~cm}$. Inner tube had an inner diameter of $6 \mathrm{~mm}$ and an external diameter of $8 \mathrm{~mm}$. Outer tube had an inner diameter of $14 \mathrm{~mm}$ and an external diameter of $16 \mathrm{~mm}$. Insulation with a thickness of $17 \mathrm{~mm}$ was wrapped on the outer tube.

Fig. 1 Experimental setup

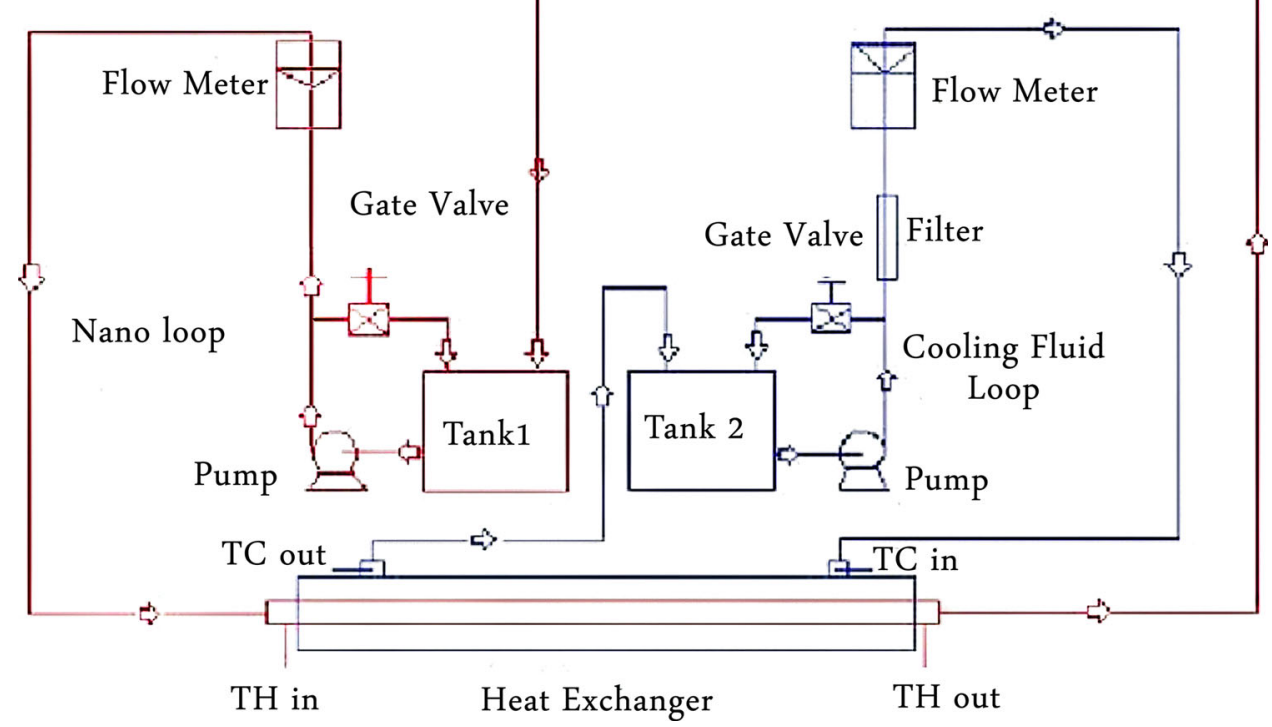


Fig. 2 Test section

(a) Schematic representation (b,

c)

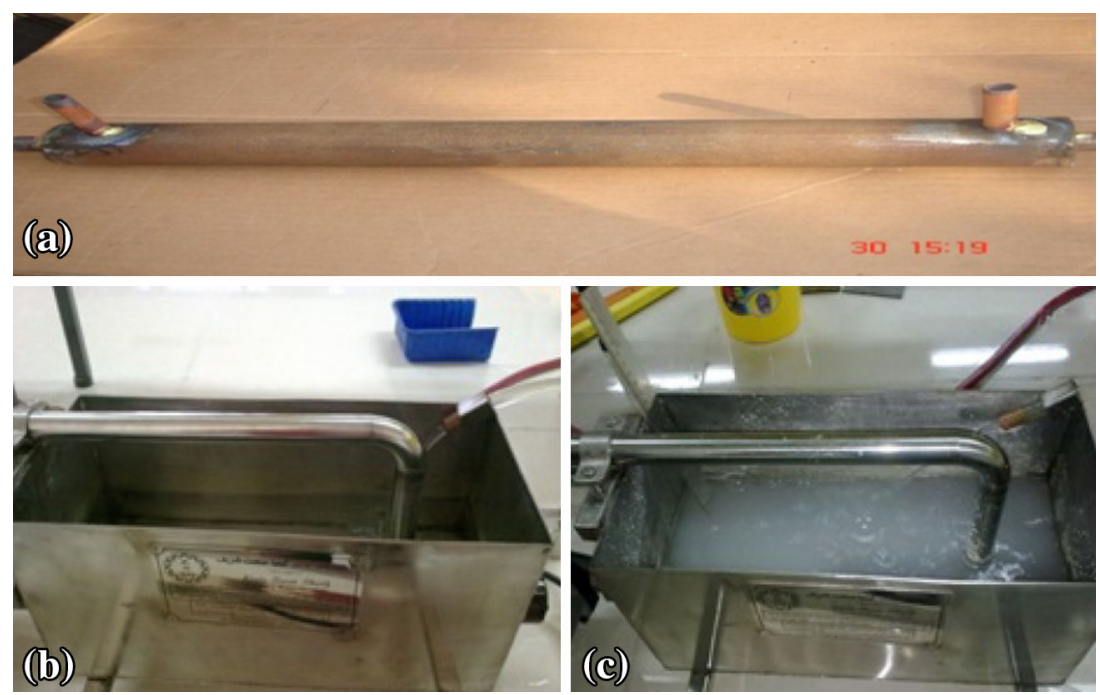

\subsection{Thermal properties of nanofluid}

The nanofluid used in the experiment was $99.0+\%$ pure alominiom oxide pre-dispersed in Water, with an average particle size of $20 \mathrm{~nm}$. The nanofluid was mixed with deionized water to prepare experimental concentrations. Figure 3 is the TEM photograph of $\mathrm{Al}_{2} \mathrm{O}_{3}$ nanoparticles with particle size about $20 \mathrm{~nm}$. It has been reported by Wen $\&$ Ding [14] that nanofluids with less than $4 \%$ nanoparticles were found to be stable and the stability lasted over a week, no intermediate mixing was considered necessary (Table 1).

\section{Data processing}

The experimental data were used to calculate overall heat transfer coefficient, convective heat transfer coefficient and Nusselt number of nanofluids with various particle volume concentrations and Peclet numbers. The thermophysical properties were calculated based on mean bulk temperature of nanofluids. The heat transfer rate of the nanofluid is:

$\mathrm{Q}=\mathrm{m}^{\circ} \mathrm{C}_{\mathrm{pnf}}\left(\mathrm{T}_{\text {out }}-\mathrm{T}_{\text {in }}\right)$

where $\mathrm{m}^{\circ}$ is the mass flow rate of the nanofluid, and $T_{\text {out }}$ and $\mathrm{T}_{\text {in }}$ are the outlet and inlet temperatures of the nanofluid, respectively. The effective density of nanofluid is:

$\rho_{\mathrm{nf}}=\left(1-\varphi_{\mathrm{V}}\right) \rho_{\mathrm{f}}+\varphi_{\mathrm{v}} \rho_{\mathrm{p}}$

Subscripts f, p, and nf refer to the base fluid, the nanoparticles, and the nanofluid, respectively. $\varphi_{\mathrm{V}}$ is the

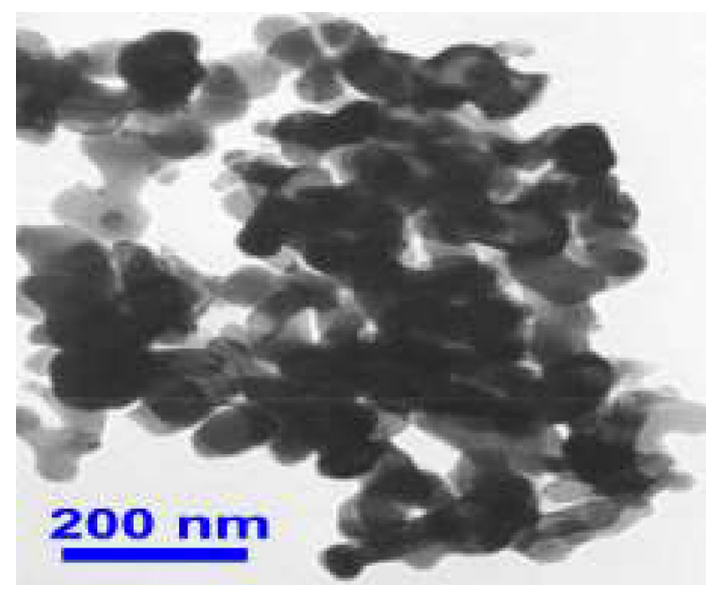

Fig. 3 TEM photograph of $\mathrm{Al}_{2} \mathrm{O}_{3}$ particles

nonoparticle volume concentration. $\mathrm{Cp}_{\mathrm{nf}}$ is the effective specific heat of the nanofluid which can be calculated from Xuan and Roetzel relation [15]:

$\left(\rho \mathrm{C}_{\mathrm{p}}\right)_{\mathrm{nf}}=\left(1-\varphi_{\mathrm{v}}\right)\left(\rho \mathrm{C}_{\mathrm{p}}\right)_{\mathrm{f}}+\varphi_{\mathrm{v}}(\rho \mathrm{C})_{\mathrm{p}}$

The heat transfer coefficient of the test fluid, $h_{i}$, can be calculated by the following equation [16]:

$\frac{1}{\mathrm{U}_{\mathrm{i}}}=\frac{1}{\mathrm{~h}_{\mathrm{i}}}+\frac{\mathrm{D}_{\mathrm{i}} \operatorname{Ln} \frac{\mathrm{D}_{\mathrm{o}}}{\mathrm{D}_{\mathrm{i}}}}{2 \mathrm{k}_{\mathrm{w}}}+\frac{\mathrm{D}_{\mathrm{i}}}{\mathrm{D}_{\mathrm{o}}}+\frac{1}{\mathrm{~h}_{\mathrm{o}}}$

where $D_{i}$ and $D_{o}$ are the inner and outer diameters of tubes respectively, $U_{i}$ is the overall heat transfer coefficient based on the inside tube area, $h_{i}$ and $h_{o}$ are the individual
Table 1 Physical properties of the nanoparticles

\begin{tabular}{llllll}
\hline $\begin{array}{l}\text { Types of } \\
\text { nanoparticles }\end{array}$ & $\begin{array}{l}\text { Nano-sized } \\
\text { particles }(\mathrm{nm})\end{array}$ & $\begin{array}{l}\text { Special surface } \\
\left(\mathrm{m}^{2} / \mathrm{g}\right)\end{array}$ & $\begin{array}{l}\text { Percent } \\
\text { purity }\end{array}$ & Appearance & $\begin{array}{l}\text { The apparent } \\
\text { density }\left(\mathrm{g} / \mathrm{m}^{3}\right)\end{array}$ \\
\hline$\gamma-\mathrm{Al}_{2} \mathrm{O}_{3}$ & 20 & $>160$ & +99 & $\begin{array}{c}\text { White } \\
\text { powder }\end{array}$ & 0.9 \\
\hline
\end{tabular}


convective heat transfer coefficients of the fluids inside and outside the tubes respectively and $\mathrm{k}_{\mathrm{w}}$ is the thermal conductivity of the tube wall. $\mathrm{U}_{\mathrm{i}}$ is given by:

$\mathrm{Q}=\mathrm{U}_{\mathrm{i}} \mathrm{A}_{\mathrm{i}} \Delta \mathrm{T}_{\mathrm{lm}}$

where $\mathrm{A}_{\mathrm{i}}=\pi \mathrm{D}_{\mathrm{i}} \mathrm{L}$ and $\Delta \mathrm{T}_{\mathrm{LM}}$ is the logarithmic mean temperature difference. The outside heat transfer coefficient can be computed by Bell's procedure [17]. Nusselt number of nanofluids is defined as:

$\mathrm{Nu}_{\mathrm{nf}}=\frac{\mathrm{h}_{\mathrm{i}} \mathrm{d}_{\mathrm{i}}}{\mathrm{k}_{\mathrm{nf}}}$

where the effective thermal conductivity $\left(K_{n f}\right)$ of the nanofluids can be evaluated by Maxwell's model that is given as following [18]:

$K_{n f}=K_{f} \frac{K_{P}+2 K_{f}-2 \varphi_{V}\left(K_{f}-K_{p}\right)}{K_{p}+2 K_{f}+\varphi_{V}\left(K_{f}-K_{p}\right)}$

Maxwell's formula shows that the effective thermal conductivity of nanofluids $\left(\mathrm{K}_{\mathrm{nf}}\right)$ relies on the thermal conductivity of spherical particles $\mathrm{K}_{\mathrm{p}}$, the thermal conductivity of base fluid $\left(\mathrm{K}_{\mathrm{f}}\right)$ and volume concentration of the solid particles $\left(\varphi_{\mathrm{V}}\right)$.

\section{Discussion and results}

Effective thermal conductivity increase of the base fluid by the addition of nanoparticles, the increase in the local heat transfer coefficient approximated as $\mathrm{k} / \delta$, where $\mathrm{k}$ is the fluid thermal conductivity and $\delta$, the thickness of the thermal boundary layer as suggested by Wen and Ding [14], Brownian motion, ballistic transport of energy carriers as suggested by Keblinski et al. [18].

\subsection{Experimental results}

Preliminary experiments with water were performed to gain experience in operating the set-up. The experiments were performed varying the nanofluid flow rate at a given concentration.

\subsection{Base line experiment using water/water}

Using nanoflouid as the heating fluid in the tube side, and water cold as the cooling medium on the outside tube, temperature measurements were taken at fluid inlet and exit positions after steady state has been reached. Steady state was determined when the temperatures remained constant with time for a $10 \mathrm{~min}$. period. The mass flow rate $(\mathrm{g} / \mathrm{s})$ of the fluid flowing inside the tube, and heat transfer rate (W) were plotted and the result shown in Fig. 4.

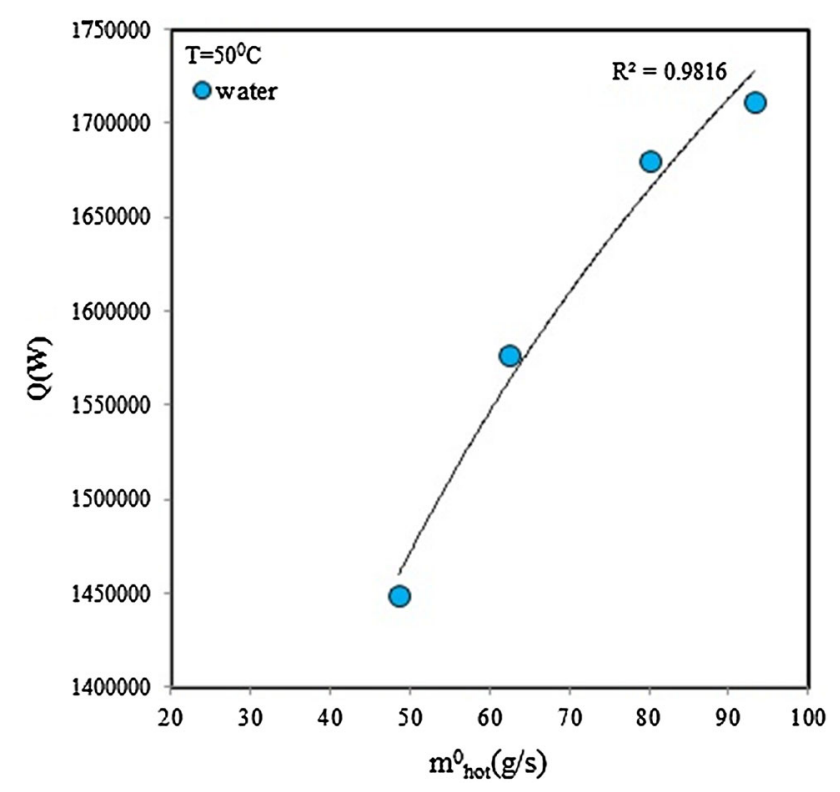

Fig. 4 Heat transfer rate-water/water exchange

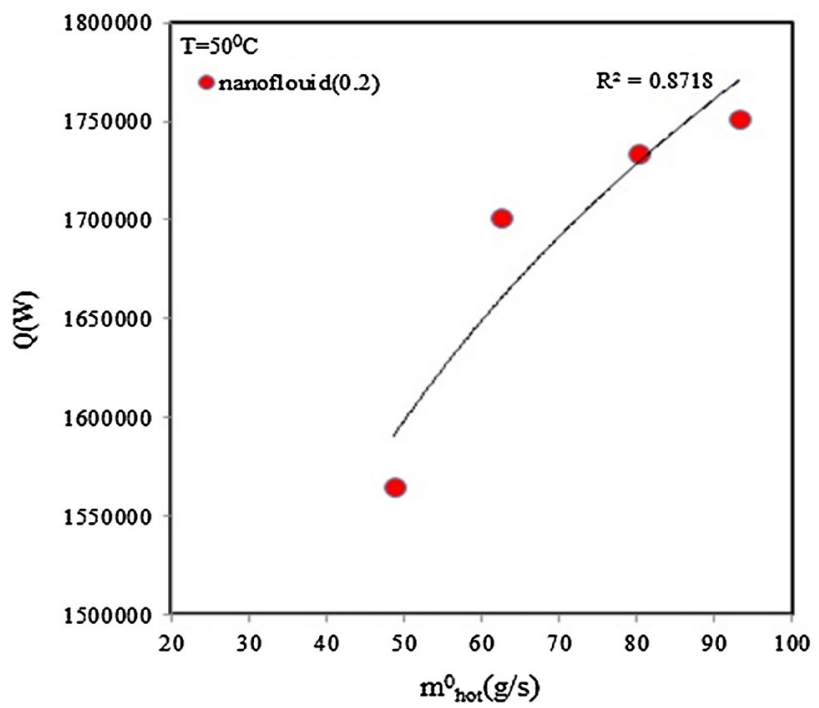

Fig. 5 Heat transfer rate-water/nano concentration, $0.2 \%$ by volume

\subsection{Heat transfer between water/nanofluid with concentration of 0.2 volumes}

A very low nanofluid concentration was used as the first nano heat transfer experiment. An increase in heat transfer rate was observed at any given flow rate. The plot of mass flow rate versus heat transfer rate is shown in Fig. 5. There is an improvement in heat flow rate due to the addition of nanoparticles even at very low concentrations. For example at a mass flow rate of $60(\mathrm{~g} / \mathrm{s})$, a $7.32 \%$ increase in heat transfer rate is observed. 


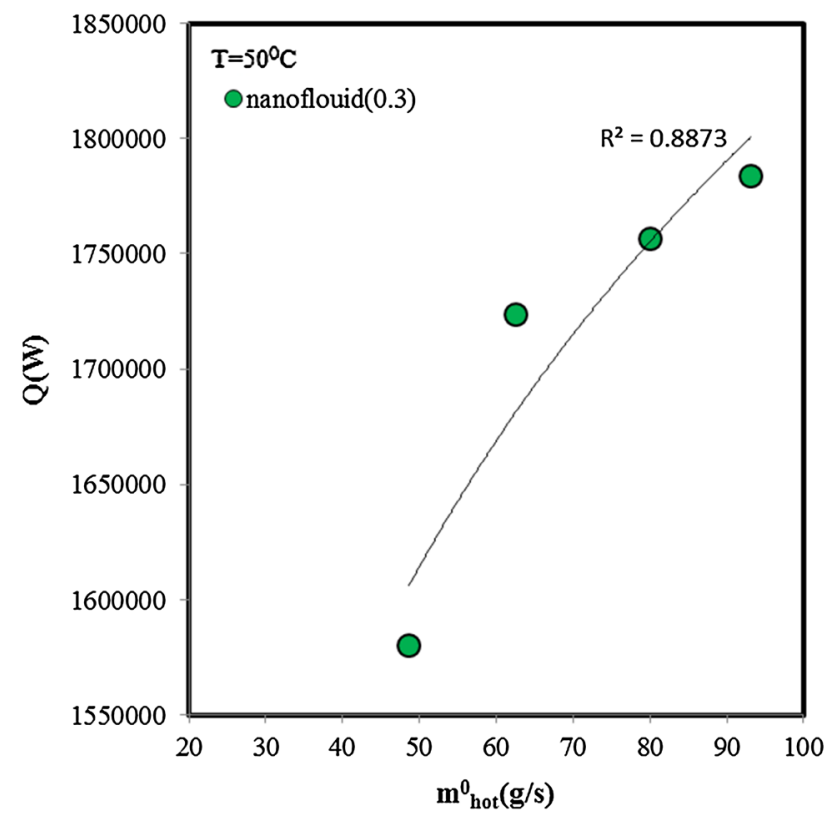

Fig. 6 Heat transfer rate-water/nano concentration, $0.3 \%$ by volume

\subsection{Heat transfer between water/nanofluid} with concentration of 0.3 volumes

As the concentration of nanoparticles in the fluid increases, a further increase in the heat transfer rate is observed. The results for the higher concentration of nanofluid is shown in Fig. 6.

\subsection{Heat transfer rate and Reynolds number}

The relationship between heat transfer rate and Reynolds number for the water/water exchange and water/nanofluid concentration of 0.1 are shown in Fig. 7.

In the present study, $\mathrm{Al}_{2} \mathrm{O}_{3}$ nanoparticles mixed with the water by $(0.1-0.2-0.3)$ vol.\% were used to investigate the effect of the Reynolds number and temperature of the flowing nanofluid and mass flow rate water on the heat transfer characteristics of the nanofluid. The experimental conditions used in this study are as follows:

(1) The Reynolds number of the nanofluid varied in the approximate range of 15,000-28,000.

(2) The temperature of the nanofluid was 40 and $50{ }^{\circ} \mathrm{C}$.

(3) The mass flow rates of the nanoflouid were 50 and $90(\mathrm{~g} / \mathrm{s})$.

As can be seen in Figs. 4, 5, 6, aluminum oxide nanofluid with concentrations of 0.2 and 0.3 had high thermal efficiency compared to the base fluid. For example, this amount is 1,450,000 for water at a constant mass flow rate and a temperature of $50{ }^{\circ} \mathrm{C}$. This amount is $1,565,000$ and

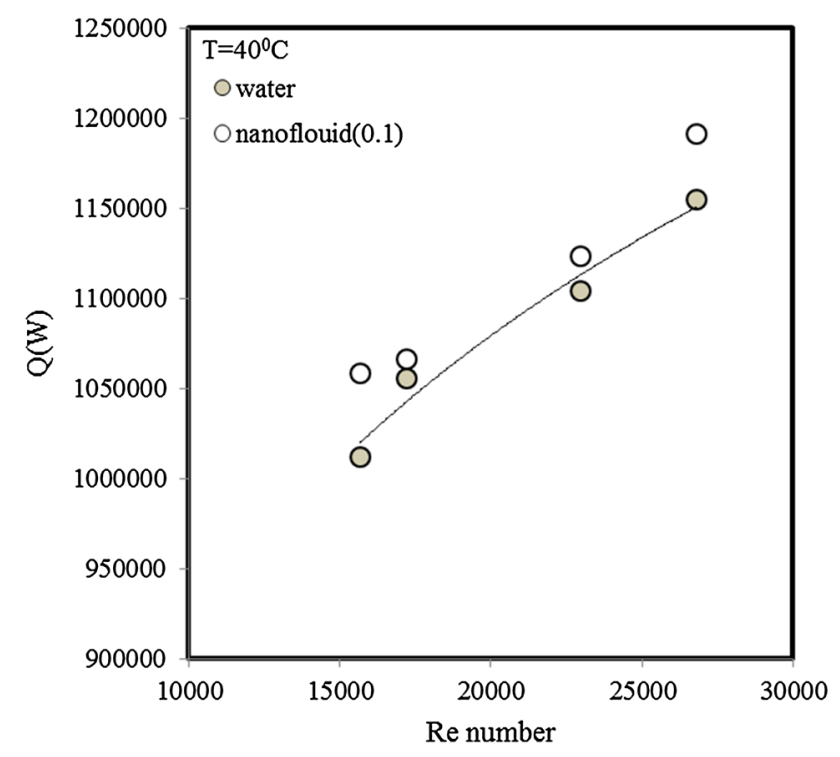

Fig. 7 Reynolds number versus heat transfer rate

$1,580,000$ for the nanofluid at the concentrations of 0.2 and 0.3 . Figure 7 also shows an increase in the heat transfer. For example, the thermal efficiency of water and nanofluid with the concentration of 0.1 are $1,103,842$ and $1,123,123$, respectively (in Reynolds of 23,000) which is approximately $1.71 \%$ higher than the heat transfer of the base fluid. This increase can be attributed to the immigration of the particles, non-uniform distribution of the thermal conductivity and viscosity of the fluid which decreases the boundary layer thickness, resulting in the delay in the development of the thermal boundary layer. Another reason is the contact of the suspended particles in the nanofluid which increases with the temperature and mass flow rate of the fluid, resulting in the increase of the contacts with the exchanger wall. Friction is also determined on the basis of the nano fluid type and properties of the heat exchanger wall. These factors have also effects on the performance and efficiency of the heat exchanger.

On the other hand, the observed moderate enhancement in heat transfer characteristics in the case of plain tube with nanofluid can be attributed to the increase in thermal conductivity of the nanofluid and low thermal dispersion. Thus it seems that the nanoparticles increase the thermal conductivity of fluid while the chaotic movement of the particles strengthens energy transport process.

\section{Conclusion}

Heat transfer performance and flow characteristic of a $\mathrm{Al}_{2} \mathrm{O}_{3}$ nanofluid flowing in a horizontal double pipe counter flow heat exchanger was experimentally investigated. 
Experiments were carried out under turbulent flow conditions. The effects of the flow Reynolds number and the temperature of the nanofluid and concentration nanoflouid on the heat transfer and flow characteristics were investigated. The following conclusions have been obtained.

- The use of $\mathrm{Al}_{2} \mathrm{O}_{3}$-water nanofluid significantly gives higher heat transfer coefficients than those of the pure base fluid.

- The nanofluid with suspended nanoparticles increases the thermal conductivity of the Mixture and a large energy exchange process resulting from the chaotic movement of nanoparticles.

- Generally, the enhancement of convective heat transfer coefficient depends on increasing of the fluid thermal conductivity and decreasing of thermal boundary layer thickness. Thermal conductivity of the nanofluids increases with increasing of the volume concentrations. Decreasing of the thermal boundary layer thickness can be due to the mobility of particles near the wall, migration of them to the center of tube, and reduction of viscosity at the wall region.

Additional work is required to investigate the effects of different particle concentrations on the heat transfer and flow features of nanofluids. Moreover, the heat transfer correlation in its simplest form will predict the heat transfer coefficient of nanofluids flowing in a horizontal doublepipe counter heat exchanger accurately.

Acknowledgments The author would like to thank Nano Technology Institution, Islamic Azad University of Shahrood and also to thank A. Hakiminejad for his helpful comments, which has helped the author in improving the quality of this manuscript.

\section{References}

1. Gut JAW et al (2004) Thermal model validation of plate heat exchangers with generalized configurations. Chem Eng Sci 59(21):4591-4600
2. Vlasogiannis $P$ et al (2002) Air-water two-phase flow and heat transfer in a plate heat exchanger. Int $\mathrm{J}$ Multiph Flow 28(5):757-772

3. Jassim EW, Newell TA, Chato JC (2006) Refrigerant pressure drop in chevron and bumpy style flat plate heat exchangers. Exp Thermal Fluid Sci 30(3):213-222

4. Dwivedi AK, Das KS (2007) Dynamics of plate heat exchangers subject to flow variations. Int $J$ Heat Mass Transf 50(13-14):2733-2740

5. Maiga SEB et al (2004) Heat transfer behavior of nanofluids in a uniformly heated tube. Superlattices Microstruct 35(3-6):543-557

6. Xuan Y, Roetzel W (2000) Conceptions of heat transfer correlations of nanofluids. Int J Heat Mass Transf 43(19):3701-3707

7. Abu-Nada E, Masoud Z, Hijazi A (2008) Natural convection heat transfer enhancement in horizontal concentric annuli using nanofluids. Int J Heat Mass Transf 35(5):657-665

8. Trisakasri V, Wongwises S (2007) Critical review of heat transfer characteristic of nanofluids. Renew Sustain Energy Rev 11(3):512-523

9. Duangthongsuk W, Wongwises S (2007) A critical review of convective heat transfer of nanofluids. Renew Sustain Energy Rev 11(5):797-817

10. Jung JY, Oh HS, Kwak HY (2009) Forced convective heat transfer of nanofluids in microchannels. Int $\mathrm{J}$ Heat Mass Transf 52(1-2):466-472

11. Li Q, Xuang Y (2002) Convective heat transfer and flow characteristic of cu-water nanofluid. Sci China Ser E 45(4):408-416

12. Choi S (1995) U.S., enhancing thermal conductivity of fluids with nanoparticles. In: Singer DA, Wang HP (eds) Development and applications of non-newtonian flows, vol 66. ASME, New York, USA, FED, pp 99-103

13. Yang $\mathrm{Y}$ et al (2005) Heat transfer properties of nanoparticle in fluid dispersions in laminar flow. Int $\mathrm{J}$ Heat Mass Transf 48(6):1107-1116

14. Wen D, Ding Y (2004) Experimental Investigation into convective heat transfer of nanofluids at the entrance region under laminar flow conditions. Int $J$ Heat Mass Transf 47(24):5181-5188

15. Xuan Y, Roetzel W (2000) Conceptions for heat transfer correlations of nanofluids. Int J Heat Mass Transfer 43:3701-3707

16. Coulson JM, Richardson JF (1999) Chemical engineering design, 3rd edn. Butterworth Heinemann, London, pp 635-702

17. Bell KJ (1963) Final report of the cooperative research program on shell-and-tube heat exchangers. University of Delaware, Engineering Experiment Station

18. Keblinski P, Philpot SR et al (2002) Mechanisms of heat flow in suspensions of nano-sized particles (nanofluids). Int J Heat Mass Transfer 45:855-863 